\title{
Seismic Strain Energy Release Pattern in Northeast India and its Adjoining Region
}

\author{
Anupama Devi ${ }^{1}$, Dr. S. Kalita ${ }^{2}$ \\ ${ }^{1 .}$ Department of Physics, Arya Vidyapeeth College, Guwahati, Assam, India \\ 2. Dept. of Environmental Science, Gauhati University, Guwahati,Assam,India
}

\begin{abstract}
Northeast India and its adjoining region constitutes an important geotectonic element of Southeast Asia and is connected to India via a narrow corridor squeezed between Nepal and Bangladesh. Geomorphologically, the entire NE India is located in an earthquake prone zone (Zone $-V$ ) of the Indian subcontinent. The strain energy release has been studied by dividing the region into in the six geo - tectonic block. It has been found that the Arakan - Yoma to be seismically active followed by Naga Hills region. It also showed that the probability of occurring an earthquake is more in the Shillong Plateau than the other five tectonic blocks. For the region as a whole there is the probability that an earthquake of intensity around 6.64 $\mathrm{mb}$ may occur as determined from strain energy bearing capacity of the region. Moreover, it has also been found that if strain energy released by a tectonic block is large it might effect the stress building process in the rocks of adjacent tectonic blocks. The iso-strain release map depicted areas of high and low seismic activity.
\end{abstract}

Key words: Geo-Tectonic block, Seismicity, Strain Energy, Iso - Strain.

\section{Introduction}

The source of energy of an earthquake is the potential energy stored in rocks due to accumulation of strain over a period of time. When the accompanying elastic stress accumulates beyond the competence of the rocks, an earthquake occurs. The strain energy release pattern of a region helps in identifying the probable source region for the occurrence of an earthquake in near future. Historical documents indicate the occurrence of destructive earthquakes in the region in the year 1548, 1596, 1642, 1663 and $1696-1714$. In modern times destructive earthquakes have occurred in $1869,1875,1897,1918,1930,1950$ and 1988. Since earthquake is a great natural hazard, it has become important to study the probability of occurrence of high magnitude earthquakes in this region due to large increase in population of the region, for developmental activities and for proper land-use planning. [1,2]. The relation between geological characteristics and occurrence of earthquakes has been studied since the very beginning of twentieth century. The study of seismic activity in a probabilistic manner for a long period of time is useful in the long range forecasting of earthquakes. [3] The method used for long range forecasting is based on the periodicity of large earthquakes (if any) and accumulation of tectonic strain. The elastic rebound of the volume of rock under stress generates the earthquake[4] and most of the strain energy stored in the rocks is released in the form of seismic waves, which radiate in all directions from its source region. However, a part of the original potential energy stored in the rock mass goes into mechanical work like raising crustal blocks against gravity or in crushing material in the fractal zone and the other part is dissipated as heat. The strain rebounded during an earthquake is proportional to the square root of the energy released[5]. Thus, earthquakes are manifestation of strain energy released from a region and its spatio-temporal behavior represents the seismo-tectonic characteristics of the region. Moreover, temporal variation of strain energy released from a seismotectonic block reveals the earthquake generation potentiality of the block at any specified time. The characteristic features and trends of stress field in a tectonic block can be investigated by examining the pattern of strain energy release over it. Assuming a linear probability of earthquake occurrences over a period of few years, a direct extrapolation of the pattern of strain release in immediate future can throw some light on the probable future earthquake activity expected in the region. The areal distribution of strain energy released helps in identifying the seismically active zones. Chouhan [6] studied the regional strain release characteristics of Indian earthquakes. He observed that every region is characterized by a certain minimum level of strain energy and strain may persist in a tectonic block even after the release of the accumulated strain by a large earthquake. Therefore, taking it as a reference, it is possible to estimate the amount of strain energy available in a tectonic block at a given time in near future. Thus, in turn, it may give an estimate about the possible maximum magnitude earthquake that may occur in the block, if the accumulated strain energy releases simultaneously [7].

\section{Geo - tectonic setting of the study region}

The study region is North-East India and its adjoining region demarcated by latitude $\left(22^{0} \mathrm{~N}-30^{\circ}\right.$ $\mathrm{N})$ and longitude $\left(89^{\circ} \mathrm{E}-98^{\circ} \mathrm{E}\right)$. Northeastern India and its adjoining territories display tectonically distinct 
geological domains occurring in intimate spatial association. Rocks representing the entire span from archean to recent, occur in this very small region. Eocene (Disang) sediments of trench facies occur in juxtaposition with those of platform facies (Jaintia) of stable shelf condition; Neogene Siwalik foredeep molasse in front of the Himalaya and Tipam molasse of Upper Assam basin in front of the Indo - Myanmaar mobile belt occur in close proximity and are separated by the Brahmaputra alluvium. Proteozoic to early Paleozonic intrusive granites are common in Meghalaya Plateau, while Tertiary granites are found in the upper reaches of the Eastern Himalaya.[8] The eastern part of this region is formed by Naga - Lushai Hills. To the south of the Shillong Plateau there is the Surma Valley region comprising of the Bengal Basin separated by an east-west trending set of faults known as Dauki fault (Figure. 1). The vertical movements have also played their part in the deposition of large thicknesses of sediments belonging to the Irrawady system of Burma and Bengal basin in India [9]. In the south, Bengal basin is open to the Bay of Bengal .The Mikir Massif is believed to be a fragmented portion of the Shillong Plateau and parted with a set of faults called Kopili fault $[9,10]$. The upper Assam Valley or the Brahmaputra Valley bounded on the southwest by the Mikir Hills and the Shillong Plateau. Geological, geophysical morphological trends and seismicity of Indo-Burma region $\left(20^{\circ}-26^{\circ}\right) \mathrm{N}$ and $\left(92^{\circ}-96^{\circ}\right) \mathrm{E}$ suggest active sub-duction. This area is a transition zone between the main Himalayan collision belt and the Indonesian arc where the Indian plate is currently sub-ducting under Asia. The Indo-Burman ranges extend from Arakan - Yoma upto Mishimi thrust belts and bulk of the ranges consist of Cretaceous to upper Eocene shales and sandstones which are considered to have undergone a major phase folding during Oligocene and Miocene.[11]

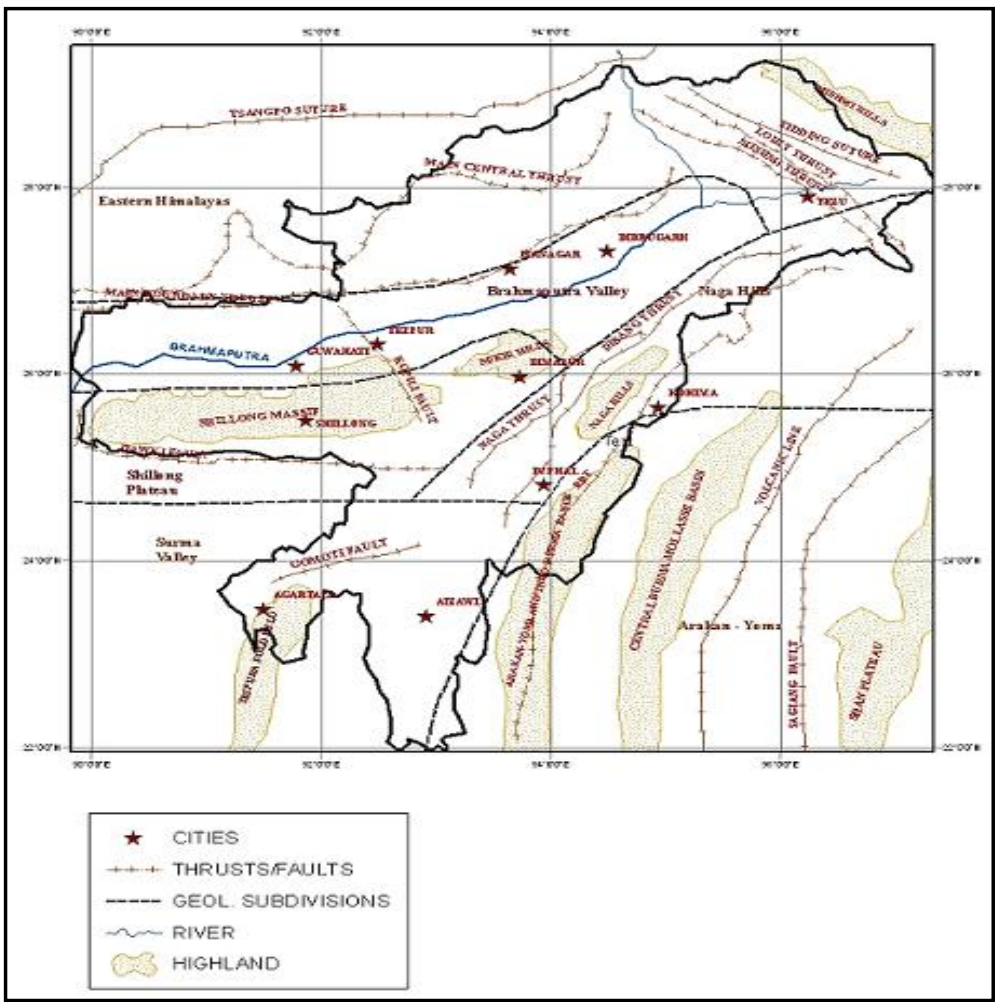

Figure 1: The map of the study region with the geo-tectonic subdivisions or zones.

The Bengal and Nicobar Fans were, for the first time, delineated and named by Curray and Moore [12]. The Bengal Fan is the largest and prodigious submarine fan in the world, with a length of about $3000 \mathrm{~km}$, a width of about $1000 \mathrm{~km}$ with varying thicknesses. It has been formed as a direct result of the India - Asia collision and uplift of the Himalayas and the Tibetan Plateau. The northeastern edges of the fans have been subducted, and some of the Tertiary turbidities cropping out in the Indo-Burma Ranges of Myanmar, the Andaman and Nicobar Islands, and in the outer arc ridge off Sumatra have been interpreted as old Bengal and Nicobar Fan sediments . It is currently supplied mainly by the confluent Ganges and Brahmaputra Rivers with smaller contributions of sediment from several other large rivers in Bangladesh and India.

The region has experienced 19 large earthquakes $(M>=7)$ during the last hundred years including the great earthquakes of Shillong (1897, M=8.7) and the Assam earthquake (1950, M=8.7) . Besides, several hundred small and micro earthquakes have also been recorded in the region. The high seismicity in the region is attributed to the collision tectonics between the Indian plate and the Eurasian plate in the north and subduction tectonics along the Indo-Myanmar range (IMR) in the east $[13,14,15,16,17]$. Verma[18] stated that the 
lithospheric subduction at the Himalayan belt ceased during Pliocene time and shallow seismic activity is the effect of continental-continental collision. Subduction, on the other hand, is still continuing in the IMR, which is evidenced by the intermediate to deep focus earthquakes in this range. Now, based on the geotectonic features, northeastern region can be divided into six zones.[8]

The zones are:

(i) The Eastern Himalayan collision belt including the trans - Himalayan Tethyan zone, the Tsangpo Suture zone (with ophiolites) and the Andean type grano - diorite margin to the north.

(ii) The Naga Hills region which comprises of Diorite - grandiorite complex of the Mishmi block with frontal folded and thrusted metamorphic belt.

(iii) The Indo - Myanmar mobile belt and the Arakan - Yoma.

(iv) The Shillong Plateau with platform sediments to the south and the east and the Mikir hills.

(v) Brahmaputra Valley with cover of alluvium and Tertiary sub - crop elements.

(vi) Surma Valley covering almost whole of West Bengal and Bangladesh with Cretaceous to Recent sediments.

\section{Datasource and Methodology}

The comprehensive data file prepared by using earthquake catalogues of ISC and USGS that are available for the study region has been used for the period $1964-2012\left(31^{\text {st }}\right.$ July). In order to study the strain energy release pattern of the region, earthquakes of magnitude greater than $3.1 \mathrm{mb}$ has been considered.

\subsection{Theory:}

Benioff's theory has been used for determining the strain energy of the study region. Benioff [4] has shown that the potential energy $E_{p}$ of a volume of rock $(w)$ is given by:

$$
\mathrm{E}_{\mathrm{p}}=0.5 \mu \mathrm{w} \mathrm{S}^{2}-\mathrm{c}^{-}
$$

where $\mu$ is the co-efficient of shear and $\mathrm{S}$ is average strain just before the earthquake. Thus the energy released by seismic waves is given by,

$$
\mathrm{E}_{\mathrm{T}}=0.5 \mu \mathrm{fw} \mathrm{S}^{2}
$$

where $f$ is the function of energy released as seismic waves.

If the strain is reduced to zero during the earthquake by some movement along a fault, then the average strain $\mathrm{S}$ is proportional to the fault displacement $\left(\mathrm{X}_{\mathrm{f}}\right)$. Thus,

$$
\mathrm{S}=\mathrm{CX}_{\mathrm{f}} \quad-\mathrm{X}_{\mathrm{f}}
$$

where $\mathrm{C}$ is the constant of proportionality. Putting the value of $\mathrm{S}$ in eq. (2) we get,

where $\mathrm{G}_{1}^{2}=0.5 \mu \mathrm{fwC} \mathrm{C}^{2}$

$$
\begin{aligned}
\mathrm{E}_{\mathrm{T}} & =0.5 \mu \mathrm{fwC}^{2} \mathrm{X}_{\mathrm{f}}^{2} \\
& =\mathrm{G}_{1}^{2} \mathrm{X}_{\mathrm{f}}^{2}
\end{aligned}
$$

Equation (4) implies that fault displacement $\left(\mathrm{X}_{\mathrm{f}}\right)$ is proportional to the square root of energy released.

$$
\log \mathrm{E}_{\mathrm{T}}^{1 / 2}=\log \mathrm{G}_{1} \mathrm{X}_{\mathrm{f}}
$$

Gutenberg and Richter [19] derived the energy, $\mathrm{E}$ of an earthquake having magnitude, $\mathrm{M}$ by the relation,

$$
\log \mathrm{E}=12+1.8^{*} \mathrm{M}
$$

Later on, they modified the relationship using strain energy released and body wave magnitude, mb, recorded at teleseismic distance and represented as :

$$
\begin{aligned}
& \log \mathrm{E}=5.8+2.4^{*} \mathrm{mb} \\
& \log \mathrm{E}^{1 / 2}=2.9+1.2 * \mathrm{mb}
\end{aligned}
$$

Now, using the magnitude energy relation of Gutenberg and Richter (eq. 6) in eq. 5, we get,

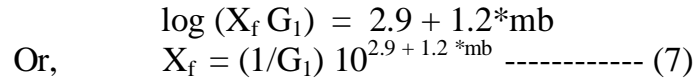

The equation (7) gives the relation between fault displacement $\left(\mathrm{X}_{\mathrm{f}}\right)$ and earthquake magnitude mb. Thus, if the magnitudes of all earthquakes occurring in any fault system over a period are known, one can plot the fault displacement (strain) that may occur during that time period. Such plots which give strain release characteristics, represent spurts of seismic activity separated by quiescent periods. The resulting curve will be a saw-tooth curve representing the exhaustion of accumulated strain caused by earthquakes.

\subsection{Application of the method to the study region : \\ 3.2.1. Temporal Variation:}

The epicentral distribution of the earthquake events considered is given in Figure. 2. The strain energy released in each of the six tectonic zone has been computed for each year by considering strain energy as the sum of the square root of energy of all the earthquakes that had occurred in each tectonic zone in the specified year [5,20]. Then, strain energy has been added up year by year to get the strain release characteristic curve. Hence the vertical line represents the release of earthquake energy $\mathrm{E}^{1 / 2}$, which again represents the strain 
factor in $\mathrm{erg}^{1 / 2}$. Since $\mathrm{S}$ is proportional to $\mathrm{E}^{1 / 2}$, the continuous lines represent the secular strain generation showing that strain accumulation is linear and may be represented as,

$$
\sum \mathrm{E}^{1 / 2}=\mathrm{A}+\mathrm{Bt}-
$$

where $\mathrm{A}$ and $\mathrm{B}$ are constants and $\mathrm{t}$ is time in years.

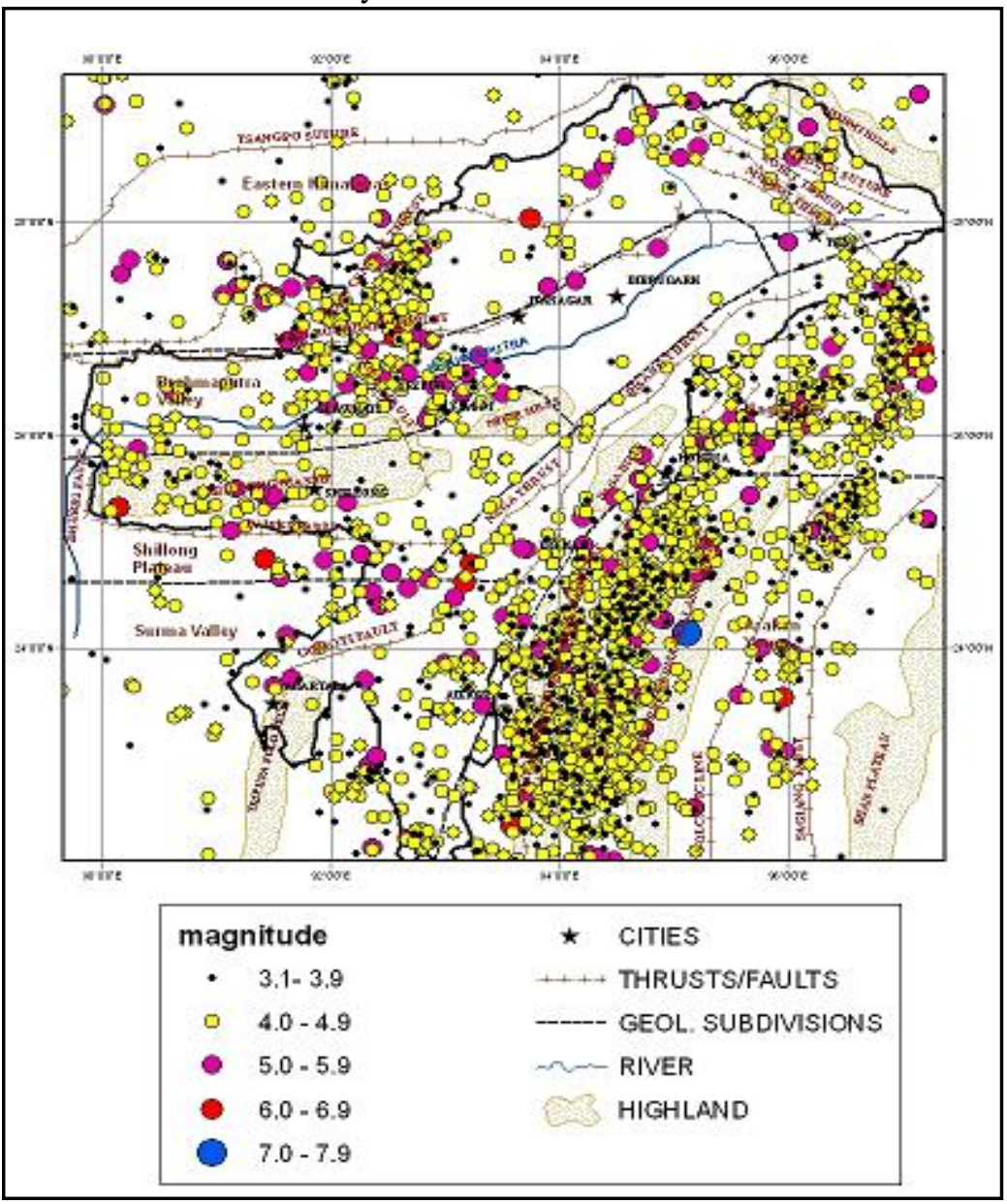

Figure. 2: Epicentral plot of the earthquake events of the study region

\subsubsection{Spatial Variation:}

The energy of each earthquake has been determined using relation (6) and iso-strain release map has been prepared. For this, the whole study region is divided into small grids having dimension $1^{0}$ by $1^{0}$. The sum total of the energy released by all the earthquakes those occurred in a particular grid are computed out and plotted at the centre of the grid. Then the isolines of energy have been drawn to prepare the iso-strain release map.

\subsection{Effect of release of strain energy by a tectonic block on nearby blocks:}

Using equation (6) the total strain energy released by earthquakes in each year by each tectonic zone is determined and is represented together graphically. Next, correlation coefficeient of the total strain energy released is computed between the six tectonic zones. Also, one - way ANOVA technique is applied here by taking earthquakes of magnitude greater than $6.0 \mathrm{mb}$. The null hypothesis taken is that when strain energy is released by a tectonic block there is some effect on adjacent tectonic blocks.

\section{Results and Observations}

\subsection{Temporal Variation of Strain Energy Released:}

Generally, it is assumed that the strain energy accumulation in a tectonic block is almost linear. But the strain energy release pattern is not linear because of the frictional force developed in the rock fractures and the temporal variation pattern of strain energy release forms a saw - toothed curve, commonly known as Benioff Graph. It gives an idea about the strain energy accumulation in a tectonic block at a particular time and is considered as complementary to the study of the magnitude - frequency relationship which defines the mean recurrence rate of any particular magnitude earthquake in a tectonic block or region. 
Moreover, it indicates the trend of activity with time and allows extrapolation for estimating strain energy accumulation in the block in near future. The study region is divided into six tectonic blocks on the basis of the concentration of earthquakes, convergence, alignment and direction of thrusting as well as structural pattern. Benioff graphs have been prepared for all the six blocks and for the region as a whole. Thus, altogether seven Benioff graphs are obtained which are shown from Figure 3 to Figure 9. The lower and the upper bound in the variation of strain energy represented by the Benioff graphs are also shown in the figures. The difference between this upper bound and the lower bound gives an idea about the strain energy bearing capacity of the respective block. The slope of the Benioff graphs gives the rate of strain energy accumulation. The rate of strain energy accumulation estimated from the graphs, approximate strain energy bearing capacity and the strain energy stored as off $31^{\text {st }}$ July, 2012 in each block and in the region as a whole are represented in table 1. On the basis of strain energy accumulation as off $31^{\text {st }}$ July, 2012 the magnitudes of the maximum possible earthquakes that may occur in the near future in different blocks and the region as a whole are computed and presented in the table.
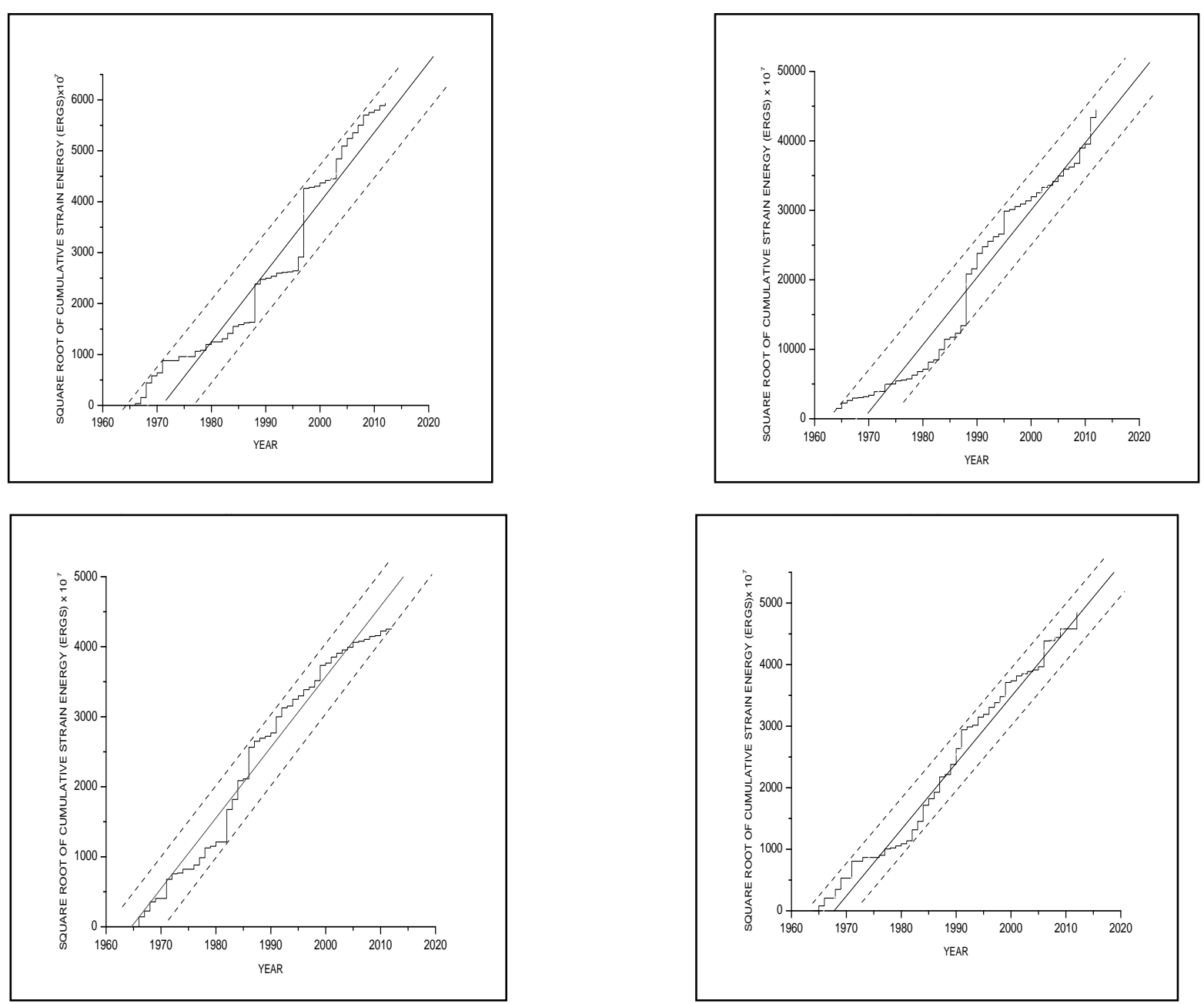

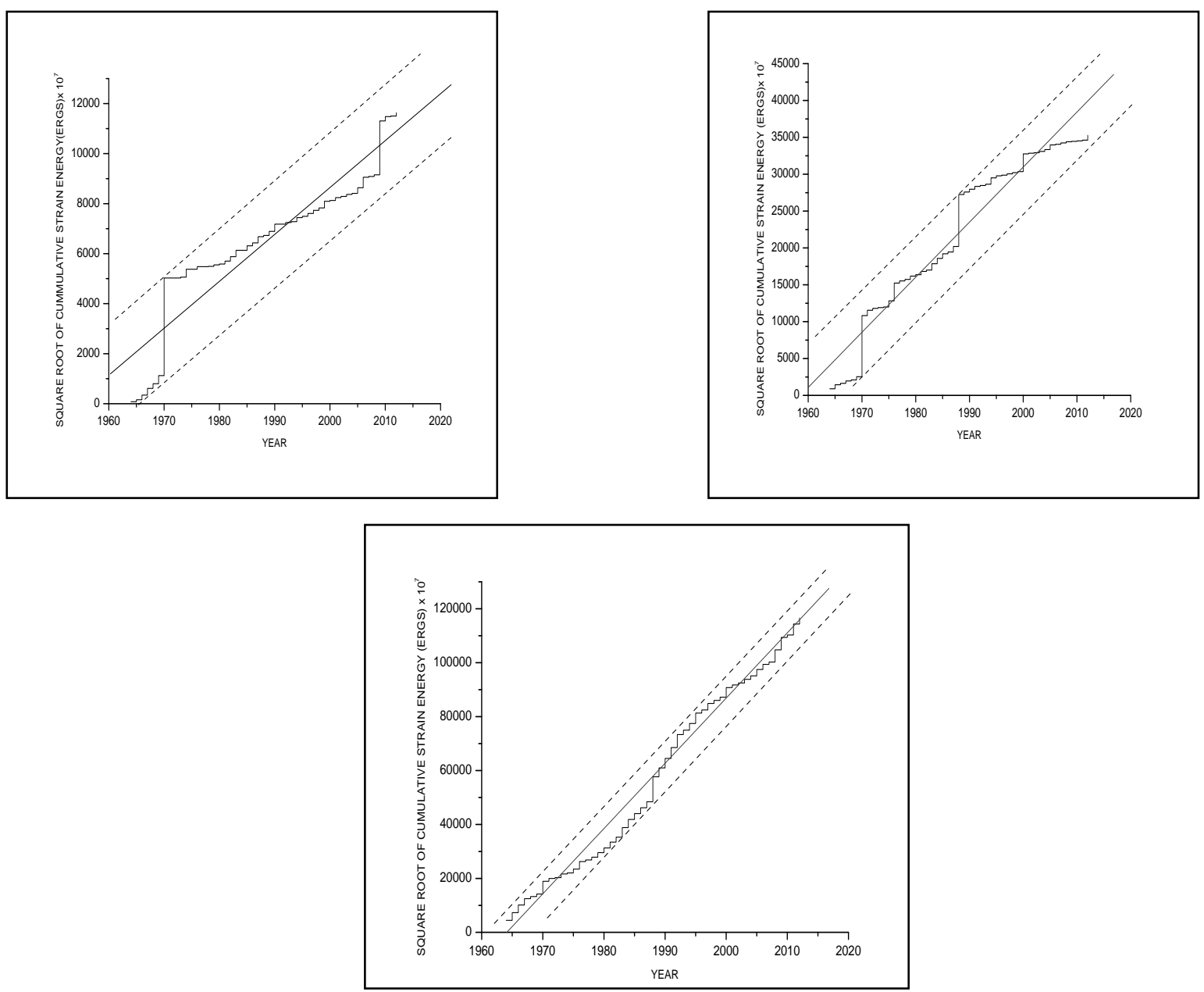

Figure 9: Whole Study Region

The observations made from the above Benioff Graphs for the six zones are:

- From fig: 3, it is seen that in the Surma Valley there is a gradual accumulation of strain energy from 1964 till around 1988 when the energy was released in the form of an earthquake, and thereafter a quiescent period was indicated till 1997 when again energy was released.

- From fig: 4 , it is seen that most of the accumulated energy in the Arakan - Yoma region was probably released around 1988. The rest of the accumulated energy is released almost regularly.

- Fig: 5 and Fig: 6 shows that in the Shillong Plateau region and Brahmaputra Valley there is a gradual accumulation of energy together with its release at regular intervals.

- In the Eastern Himalayas, as seen from fig: 7 there was an accumulation of energy till 1970 when it was released. After that there is a period of low seismic activity with gradual accumulation of energy.

- Strain energy release pattern of Naga hills as shown in fig: 8, depicts gradual accumulation of energy till it was released in 1970. Then, there was a quiescent period till 1988 when energy was released again. Thereafter, it is seen that small amount energy was again released in 2000.

- The strain energy releases at a regular interval in the whole study region together with a gradual accumulation of energy as shown in fig: 9. 
Table 1. Strain energy accumulation in the study region as off $2012(31-07-2012)$

\begin{tabular}{|c|c|c|c|c|}
\hline Region & $\begin{array}{l}\text { Rate of square root of } \\
\text { strain energy } \\
\text { accumulation (in } \\
\text { ergs/year) } x 10\end{array}$ & $\begin{array}{c}\text { Estimated } \\
\text { maximum strain } \\
\text { bearing capacity } \\
\text { (in ergs) x } 10\end{array}$ & $\begin{array}{l}\text { Strain energy } \\
\text { due for release } \\
\text { as of } 2012\left(31^{\text {st }}\right. \\
\text { July) } \\
\text { (in ergs) } \times 10^{20}\end{array}$ & $\begin{array}{l}\text { Size of the } \\
\text { probable } \\
\text { earthquake as } \\
\text { of } 31^{\text {st } J u l y, ~} \\
2012(\mathrm{mb})\end{array}$ \\
\hline Arakan - Yoma & 8.8445 & 118.81 & 5.59 & 6.22 \\
\hline Naga Hills & 7.97 & 102.73 & 88.34 & 6.72 \\
\hline Eastern Himalayas & 1.6993 & 17.73 & 2.44 & 6.07 \\
\hline $\begin{array}{c}\text { Brahmaputra } \\
\text { Valley }\end{array}$ & 1.0421 & 0.8172 & 0.1604 & 5.58 \\
\hline Shillong Plateau & 1.0212 & 0.998 & 0.993 & 5.91 \\
\hline Surma Valley & 1.2359 & 2.55 & 0.153 & 5.57 \\
\hline Whole Region & 21.5383 & 359.32 & 54.63 & 6.64 \\
\hline
\end{tabular}

From the Table 1. above it is seen that the strain energy bearing capacity is maximum in the Arakan Yoma region and it is minimum in the Brahmaputra Valley which is in accordance to the seismic activity as observed in the epicentral plot of the study region (Fig. 2). Rate of strain accumulation is maximum in the Arakan - Yoma region and minimum in the Shillong Plateau. It is also seen that in the Shillong Plateau amount of strain energy due to release as on $31-07-2012$ is comparable with the estimated strain bearing capacity of the rocks of the region. Hence the probability of occurrence of earthquake in that region in the near future is greater than the other regions. The study of strain energy bearing capacity of a region is very helpful in estimating the size of the future earthquakes that might occur in the region. These curves provide a reference and minimum strain energy level which gives an estimate about the amount of stored strain in the region and hence, the possible size of the earthquake that may occur if the entire stored strain would release at a time. From the table above, it is observed from the amount of strain energy accumulated in the study region as off $31^{\text {st }}$ July, 2012, that there is a probability of occurrence of an earthquake of magnitude of $6.64 \mathrm{mb}$ in the area. Also, it is seen that the size of most probable earthquake is maximum at Naga Hills.

The above results show that the earthquake risk in the area is not so high. The size of the maximum magnitude earthquake that may occur in each of the six tectonic blocks as well as the region as a whole indicate that only moderate earthquakes are likely in the near future.

\subsection{Spatial Variation of Strain Energy Released:}

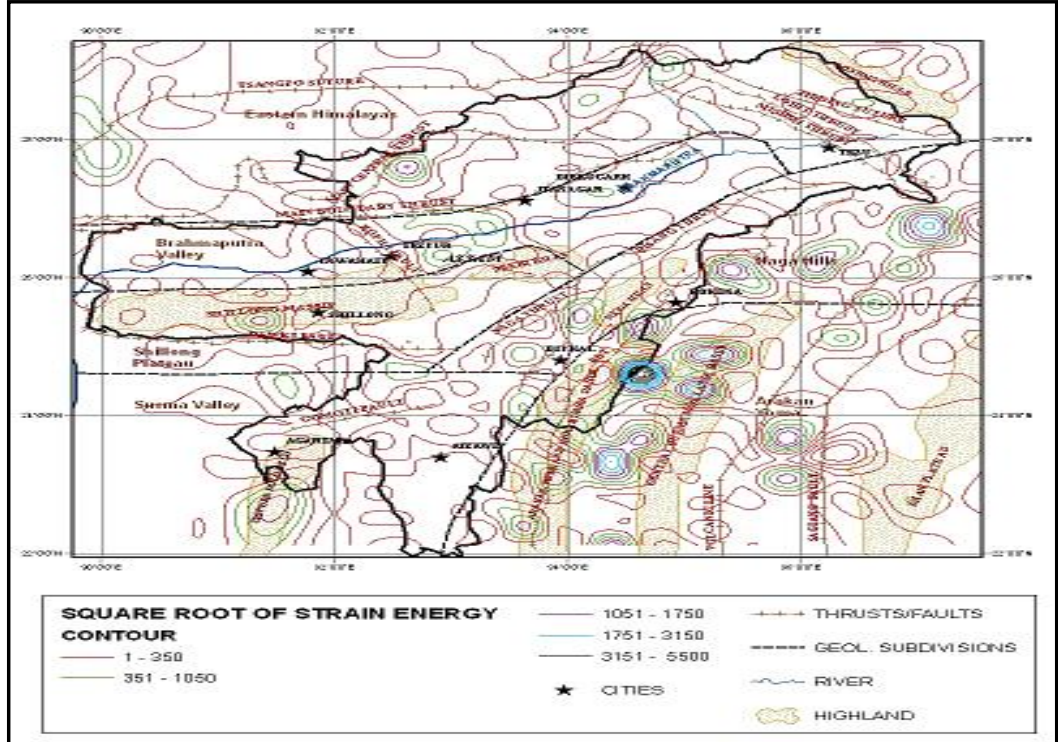

Figure 10: Iso-strain energy (ergs) $\times 10^{7}$ release map of the study region with grid $\left\{(1)^{0} \times(1)^{0}\right\}$ 
Iso-strain release map of the study region have been prepared at an interval of $\left\{(1)^{0} \mathrm{x}(1)^{0}\right\}$ and is presented in Fig. 10. The map reveals that high strain energy is released at Central Burma Mollasse Basin along the Eastern Boundary thrust. This may be due to bending of the subducting Indian plate as well as external forces due to overriding Burmese plate in this zone. The seismic events of Indo - Burma region has deep focus due to subduction of the Indian Plate under the Burmese Plate.[21] It is also high at the Naga Hills tectonic block near the Lohit and Mishmi Thrust. Since these are made up of diorite and granodiorite complex with a frontal belt of high grade schists and migmatites, and inner belt of low grade schist with crystalline limestone and serpentinite lenses. The 1950 Assam Earthquake had its epicenter in the Po Chu fault which is at the NW extremity of Mismi Massif [8]. It is medium along the MCT and MBT. This may be the result of shallow seismic events due to collision tectonics between the Indian Plate and the Eurasian Plate [15,18,21,22]. The Shillong Plateau show medium release of strain energy. This is due to the occurrence of Upper Cretaceous carbonatite - ultramafic complex along a NE fracture zone in the east - central part of the plateau. The region between the volcanic line and Sagiang fault at the Indo - Burma boundary also show medium release of strain energy which is attributed to the presence of the $200 \mathrm{~km}$ wide and $1400 \mathrm{~km}$ long Palaeogene - Neogene Central Myanmar Sedimentary Basin. The strain energy released is low in the Brahmaputra Valley except near the Kopili fault where it is medium as a consequence of transverse tectonics that extend to the Bhutan Himalaya. In fact, at present this fault which seperates the Shillong Plateau and the Mikir Massif by strike slip movement has been identified as one of the most active fault of the Brahmaputra Valley [23,24]. The studies carried out by Nandy and Dasgupta[25] and again by Nandy[26] indicated future probability of occurrence of an seismic event of significant size in the region around the Kopili fault and the Shillong Plateau. But in the Surma Valley near the Open Tripura Frontal Fold it is low. Since there is a thick deposit of sediments and locking of the Indian plate below the basin.[8]. Iso - strain contour map also indicated crustal homogeneity of Brahmaputra valley and also the presence of Assam gap[2]. Thus, the strain energy release map reflects the areas of high and low seismic activity, which is very much applicable in the seismic risk analysis.

\subsection{Effect of release of strain energy by a tectonic block on other nearby blocks: \\ 4.3.1 From Graph:}

Cumulative strain energy (square root) released in each tectonic block is shown in fig. 11 . On $29^{\text {th }}$ July, 1970 an earthquake of magnitude $6.4 \mathrm{mb}$ occurred with its epicenter at the Naga Hills tectonic block ( $26.02^{\circ} \mathrm{N}$ and $95.37^{\circ} \mathrm{E}$ ). From fig. 11 it is observed that the occurrence of this earthquake is indicated by the release of strain energy. As this released energy propagates along the earth's crust as waves, it triggers the release of energy in the nearby tectonic block also (Eastern Himalayas) as seen in fig. 11. Again on $6^{\text {th }}$ August, 1988, an earthquake of magnitude $7.3 \mathrm{Ms}$ or $7.1 \mathrm{mb}$ occurred with its epicenter at the Indo - Myanmaar border i.e. in the Arakan - Yoma region $\left(24.14^{0} \mathrm{~N}\right.$ and $95.12^{0} \mathrm{E}$ ). From the Benioff curve below (fig. 11.) it is seen that this event is indicated by the release of strain energy in the Arakan - Yoma tectonic block triggering the release of energy in the Naga Hills.

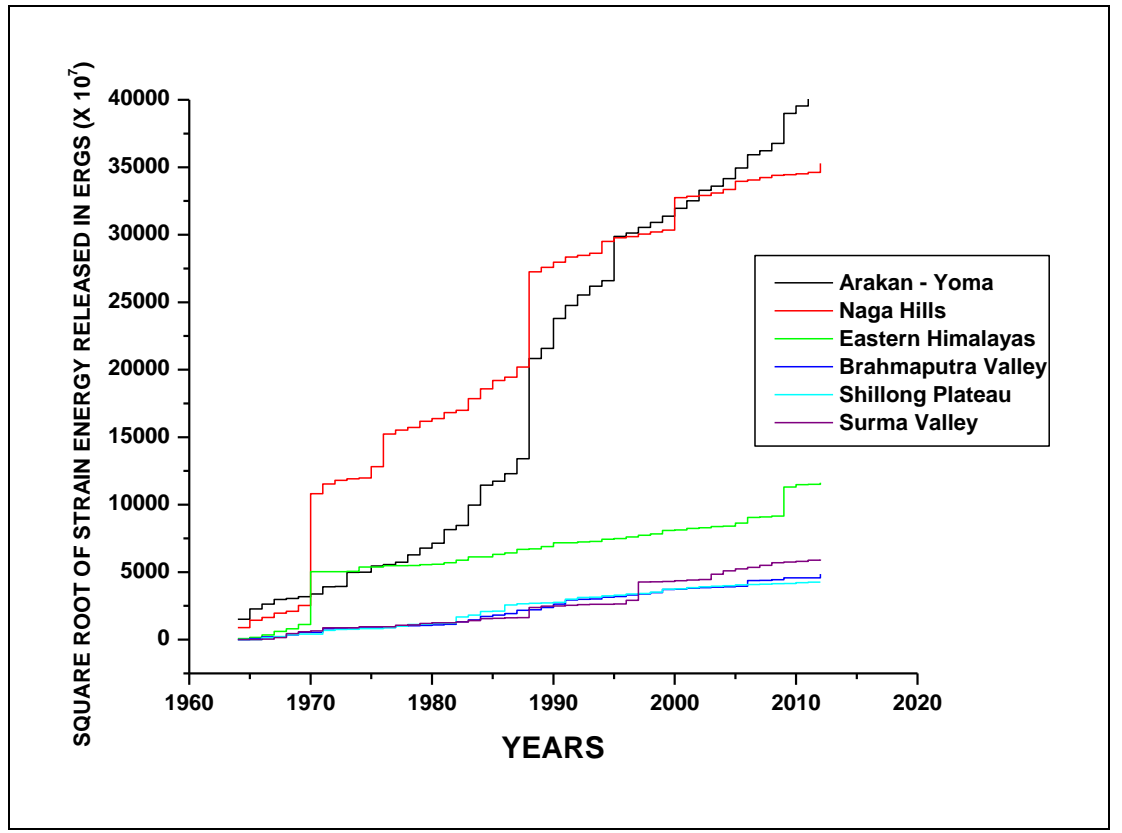

Figure 11: Cumulative strain energy (square root) release curve of all the six tectonic blocks 
This phenomenon may be attributed to the fact that the released strain energy dissipates as heat energy along the fault and as seismic vibration which causes the rocks to go back to their original undeformed shape. Due to this movement and also due to the propagation of seismic vibration as waves along the earth's crust, stress builds up in the nearby tectonic blocks causing the release of strain energy in these blocks. [5] Thus it can be said that if strain energy released by a tectonic block is large it might effect the stress building process in the rocks of adjacent tectonic blocks.

\subsubsection{By statistical method (ANOVA):}

ANOVA technique is applied to investigate any number of factors which are hypothesized or said to influence the dependent variable. Here we have applied one - way ANOVA technique to see the effect of strain energy released by a tectonic block (Arakan - Yoma block) on the other five blocks by taking only those earthquakes whose magnitude is greater than or equal to $6.0 \mathrm{mb}$. From the table 2 . below, it is seen that the calculated value of $\mathrm{F}$ is less than the value of $\mathrm{F}$ obtained from table at $5 \%$ level of significance. Thus, this analysis supports the null hypothesis of dependence of strain energy released by a tectonic block on strain energy released by a nearby block provided the earthquake event is equal or greater than $6.0 \mathrm{mb}$. Thus, the strain energy released in a tectonic block due to the occurrence of an earthquake may effect the strain energy release pattern of the rocks of adjacent tectonic blocks.

Table 2: ANOVA table

\begin{tabular}{|c|c|c|c|c|c|}
\hline $\begin{array}{c}\text { Source of } \\
\text { variation }\end{array}$ & $\begin{array}{c}\text { (Sum of } \\
\text { Squares) SS }\end{array}$ & $\begin{array}{c}\text { (degree } \\
\text { of } \\
\text { freedom) } \\
\text { d.f. }\end{array}$ & $\begin{array}{c}\text { (Mean } \\
\text { Square) MS }\end{array}$ & F-ratio & $\begin{array}{c}5 \% \text { F - limit } \\
\text { (from table) }\end{array}$ \\
\hline $\begin{array}{c}\text { Between } \\
\text { Sample }\end{array}$ & 67139064 & 5 & 13427813 & 2.679766 & 2.772853 \\
\hline $\begin{array}{c}\text { Within } \\
\text { Sample }\end{array}$ & 90194664 & 18 & 5010815 & & \\
\hline Total & $1.57 \times 10^{8}$ & 23 & & & \\
\hline
\end{tabular}

\subsubsection{Determination of correlation co-efficient of the strain energy released between the tectonic blocks:}

From the table 3. below, it is observed that the value of correlation coefficient is positive in Naga Hills - Arakan Yoma, Naga Hills - Surma Valley, Naga Hills - Eastern Himalayas, Arakan Yoma - Surma Valley, Arakan Yoma - Brahmaputra Valley and Shillong Plateau - Brahmaputra Valley tectonic blocks. This value is negative between all the other tectonic blocks. The positive value implies that when strain energy is released by a tectonic block it is also released in the corresponding block while negative value indicates accumulation of energy in the other block.

Table 3: Correlation coefficient between different tectonic blocks

\begin{tabular}{|c|c|c|c|c|c|c|}
\hline Block & $\begin{array}{c}\text { Eastern } \\
\text { Himalayas }\end{array}$ & Naga Hills & Arakan Yoma & $\begin{array}{l}\text { Surma } \\
\text { Valley }\end{array}$ & $\begin{array}{l}\text { Shillong } \\
\text { Plateau }\end{array}$ & $\begin{array}{c}\text { Brahma. } \\
\text { Valley }\end{array}$ \\
\hline $\begin{array}{c}\text { Eastern } \\
\text { Himalayas }\end{array}$ & 1 & -------- & --------------- & ------------ & ------------ & ------------ \\
\hline Naga Hills & 0.690 & 1 & -------------- & ------------- & ----------- & ----------- \\
\hline Arakan Yoma & -0.093 & 0.471 & 1 & ------------ & ----------- & ---------- \\
\hline $\begin{array}{l}\text { Surma } \\
\text { Vallev }\end{array}$ & -0.049 & 0.183 & 0.282 & 1 & ----------- & ----------- \\
\hline $\begin{array}{l}\text { Shillong } \\
\text { Plateau }\end{array}$ & -0.134 & -0.172 & -0.092 & -0.079 & 1 & \\
\hline $\begin{array}{c}\text { Brahma. } \\
\text { Valley }\end{array}$ & -0.074 & -0.200 & 0.031 & -0.040 & 0.405 & 1 \\
\hline
\end{tabular}

From the above values it is seen that the correlation coefficient is maximum between Naga Hills Eastern Himalayas followed by Naga Hills - Arakan Yoma which is in accordance with fig.11. The values of correlation coefficient obtained thus indicate that if strain energy released by a tectonic block is significant then it may influence the accumulation and release of energy by the rocks of the nearby tectonic blocks. 


\section{Conclusion}

region that,

It can be inferred from the study of strain release pattern of the six tectonic blocks of the study

- Eastern side of the region consisting of the Naga Hills and Arakan - Yoma block is seismically more active than the other regions.

- The strain energy due to release as off 2012 ( $31^{\text {st }}$ July) of the study region is $54.63 \times 10^{20}$ ergs which indicates that there is a probability of occurrence of an earthquake of magnitude around $6.64 \mathrm{mb}$ in the near future.

- Again, it has been observed that the strain energy bearing capacity of the rocks of the Arakan - Yoma region is high as compared to other regions. Moreover, in the Shillong Plateau amount of strain energy due to release as on $31-07-2012$ is comparable with the estimated strain bearing capacity of the rocks of the region. Hence the probability of occurrence of earthquake in that region in the near future is greater than the other regions.

- It is also seen that there is some effect of release of energy by a tectonic block on nearby blocks when earthquakes of magnitude greater than $6.0 \mathrm{mb}$ occur.

- From the iso-strain release map we get some idea about the crustal structure of the study region and also areas of different seismic activity could be identified.

The present study has great significance as a number of devastating earthquakes have occurred in this region. Again, knowledge of the size of the most probable earthquake that might occur in the region will help the structural and architect engineers while designing buildings. Thus, a detailed analysis of strain energy release pattern of the region would be very useful in minimizing the loss of life and property due to a seismic event.

\section{References}

[1] H.C. Goswami, and S.K. Sarmah,, Probabilistic Earthquake Expectancy in the North-East Indian region. Bulletin of the Seismological Society of America, Vol. 72, 1982, 999 - 1009.

[2] K.N. Khattri, Great Earthquake, Seismicity Gaps and Potential for Earthquake Disaster along Himalayan plate boundary. Tectonophysics. Vol. 138, 1987, $79-92$.

[3] H.N. Srivastava, Forecasting Earthquakes (National Book Trust, India, 1983).

[4] H. Benioff, Seismic evidence for fault origin of oceanic depth. Bulletin of the Seismological Society of America, Vol. 60, $1949,1837-1856$.

[5] H. Benioff, Global strain accumulation and release and reserved by great earthquakes, Bulletin of the Seismological Society of America, Vol. 56,1951, $331-338$.

[6] R.K.S. Chauhan, Regional strain energy release characteristics for Indian region. Bulletin of the Seismological Society of America, Vol. 56, 1966, $749-754$.

[7] H.C. Goswami, A Study of seismic risk in the North-East Indian region, doctoral thesis, Gauhati University, Guwahati,1984.

[8] D.R. Nandy, Geodynamics of Northeastern India and the adjoining region ( ABC Publications, Calcutta, 2001)

[9] P. Evans, The tectonic framework of Assam. Geological Society, India, Vol.5, 1964, 80-90.

[10] D.R. Nandy, Geological set up of the eastern Himalaya and Patkoi-Naga-Arakan-Yoma (Indo-Burma) hill ranges in relation to the Indian plate movement. Himalayan Geol. Soc. IIA, Misc. Publ., Vol. 41, 1976, 205-213.

[11] A.H.G. Mitchell, Phanerozoic plate boundaries in mainland SE Asia, The Himalayas and Tibet. Geol. Soc. London J., Vol. 138, 1981, 109-122.

[12] J.R. Curray, D. G. Moore, L. A. Lawver, F. J. Emmel, R. W. Raitt, M. Henry, and R.Kieckhefer, Tectonics of Andaman Sea and Burma. American Association Petro. Geolog. Memoir, Vol. 29, 1979, 189-198.

[13] J.F. Dewey and J.M. Bird, Mountain belts and the new global tectonics. Jour. Of Geophys. Res., Vol. 75, 1970, $2625-2647$.

[14] J.R. Kayal, Seismicity of Northeast India and surroundings - development over the past 100 years, Jour. Of Geophysics, Vol. 19(1), 1998, 9-34.

[15] P. Molnar and P. Tapponnier, Cenozoic tectonics of Asia: effects of a continental collision. Science, Vol. 189, 1975, 419-426.

[16] P. Molnar, and P.Tapponnier, Relation of the tectonics of Eastern China to the India-Eurasia collision: application of slip-line field theory to large-scale control tectonics. Geology, Vol. 5, 1977, 212-216.

[17] S.K. Sarmah, The probability of occurrence of a high magnitude earthquake in Northeast India. Journal Of Geophysics, Vol. 20(3), 1999, 129-135.

[18] R.K. Verma, M. Mukhopadhyay, and M.S.Ahluwalia, Seismicity, gravity and tectonics of Northeast India and Northern Burma. Bull. Seism. Soc., Vol. 66, 1976, 1683-1694.

[19] B. Guttenberg and C.F. Richter, Magnitude and energy of earthquake, Journal of Am. De.Geophysics, Vol. 9,1956,1-15.

[20] A.R. Ritsma, A statistical study of the seismicity of the earth, Material and Geophysics Surv. Indonesia, $1954,46-47$.

[21] S. Baruah, and D. Hazorika, A GIS based tectonic map of Northeastern India, Current Science, Vol. 95 (25), 2008.

[22] K.N. Khattri, and A.K. Tyagi, Seismicity patterns in the Himalayan plate boundary and identification of the areas of high seismic potential.Tectonophysics, Vol.96, 1993, 281-297.

[23] J.R .Kayal, S.S. Arefiev, S. Baruah,D. Hazarika, N. Gogoi, A. Kumar,S.N. Chowdhury, and S. Kalita, Shillong Plateau earthquakes in Northeast India region: Complex tectonic model Current Science Vol. 91 (1), 2006, 109-114.

[24] P.M. Bhattacharya, S. Mukhopadhyay,R.K. Majumder, and J.R. Kayal, 3-D Seismic Structure of Northeast India Region and Its Implication for Local and Regional Tectonics. Journal of Asian Earth Sciences, Vol. 33 No. 1-2, 2008, 25-41.

[25] D.R. Nandy and S. Dasgupta, Application of remote sensing in regional geological studies - a case study in Northeastern part of India, Proceedings International Seminar On Photogrametry and remote sensing for developing countries, Vol.1, 1986, T.4-P/6.1 T.4-P/6.4.

[26] D.R. Nandy, Geodynamics of Northeastern India and the adjoining region, Geological Survey of India, Spl. Pub. Vol. 85, $2005,49-59$. 